\title{
Assessing the scientific and educational value of case reports: an editor's view
}

\author{
Shigeru Ehara
}

Received: September 22, 2010 / Accepted: October 13, 2010

(C) Japan Radiological Society 2011

I believe that publishing case reports is a worthwhile endeavor of scientific publications. As clinical radiologists comprise most of our readers, publications directly connected to clinical observations have some value in our clinical practice. Many important facts have been published initially as case reports. Particularly, case reports are suited to describe a new disease entity, alert other clinicians to unexpected treatment responses, and inform us about an innovative treatment for a rare condition, none of which situations is suitable for a full clinical trial. ${ }^{1}$ In addition, case reports promote further research.

However, in the current evaluation system of academic journals, publication of many case reports negatively affects the rating of an academic journal. Many journal editors are having to discontinue or decrease the number of case reports they publish to improve their journals' ratings (i.e., an impact factor). Publishing case reports in this journal may continue, but the priority of publishing case reports needs be assessed more strictly. Our policy on case reports at the Japanese Journal of Radiology is indicated in the Instruction to Authors in each issue. ${ }^{2}$

Assigning a priority rating to case reports is a difficult task. First, the scientific value of the report is determined by what case is being described. In this respect, I think that it is appropriate to include one of the comprehensible categorization systems of what is acceptable, originally published in Skeletal Radiology. ${ }^{3}$

S. Ehara $(\bowtie)$

Department of Radiology, Iwate Medical University, 19-1

Uchimaru, Morioka 020-8505, Japan

Tel. +81-19-651-5111; Fax +81-19-651-7071

e-mail: ehara@iwate-med.ac.jp
1. Initial report of a new disease entity

2. Supporting evidence of a new disease entity (not more than a few cases after the initial case report)

3. Report of a new imaging examination

4. Case with an unusual clinical course that is contrary to our current knowledge

5. New treatment and outcome

6. Well-described but rare disease (not more than five cases reported)

7. Case with rare (fewer than five cases) but not unexpected findings

8. Uncommon disease (10-15 cases reported)

9. Well-described disease with educational value

Among the above categories, we can assign only a low priority to the reports of the categories 6-9. A new treatment and its results (category 5) should be published in a better-controlled (case-control or randomized controlled trial) study. Case reports of category 5 are acceptable only when the disease is rare. The reports of allegedly category 1 or 2 often turn out to be category 6,7 , or 8 because of an incomplete literature search.

In addition, I think that there may be a room for reports with educational value. Educational messages to be conveyed to the readers are important, and they need to be emphasized. Acceptable educational case reports have been classified as having the following objectives. ${ }^{4}$

- Enhance awareness of the rare disorders to facilitate diagnosis

- Elucidate new aspects on etiology/pathogenesis of a disorder

- Present a new principle or evidence to support or to revise current theory

- Clarify a misunderstood condition or treatment response 
- Describe examples of how to anticipate and/or avoid future problems

Finally, clinical cases are in themselves unique, and experiences of particular clinical radiologists are also unique. To report them, however, there should be more than just variations of individual cases in the disease entity. For example, what one physician views as a discovery may be seen as only a routine clinical scenario by another. Thus, the authors of case reports are expected to have thorough knowledge of the disease entity being reported and to have undertaken a vigorous literature search.

\section{References}

1. Scott JR. In defense of case reports. Obstet Gynecol 2009;114:413-4.

2. Anonymous. Policy on case reports (in Instruction to Authors). Jpn J Radiol 2009-2010.

3. Rosenthal DI. What makes a case report publishable? Skeletal Radiol 2006;35:627-8.

4. Chelvarajah R, Bycroft J. Writing and publishing case reports: the road to success. Acta Neurochir (Wein) 2004;146:313-6. 